\title{
POWER QUALITY MEASUREMENTS AND MITIGATION OF DISTURBANCES DUE TO PWM AC DRIVES
}

\author{
P. E. Issouribehere (*), G. A. Barbera (*), F. Issouribehere (*), Member, IEEE, and H. G. Mayer (*)
}

\begin{abstract}
Variable speed AC drives are finding their place in all types of industrial and commercial loads. One important application of these drives is in process control, controlling the speed of fans, compressors, pumps and blowers. However, there are many line (source) design parameters frequently overlooked. A pipeline for transporting synthetic crude oil was installed in Argentina and variable frequency drives (VFD) were employed to control the centrifugal pumps, in order to provide flow and pressure control. During the commissioning and start-up program, the IITREE-LAT performed Power Quality measurements and EMC studies in the petroleum process plants. The first part of the paper deals with the problem of commonmode voltages and its mitigation. In the second part of the paper, the preservation of the reference levels for the supply voltage and emission limits for the petroleum plant as a customer is evaluated by measurements of harmonics content in both voltage and current. An LC resonance problem was found and a practical solution was implemented.

The fulfillment of power quality limits for both International and Argentinian standards is assessed.

Finally, the behavior of the VFD - in terms of PQ indicators under different load conditions is analyzed in detail.
\end{abstract}

Index Terms-Harmonics, Total harmonic distortion (THD), variable frequency drives (VFD), power factor, current source inverter (CSI), Electromagnetic Compatibility (EMC), Power Quality (PQ).

\section{INTRODUCTION}

$\mathrm{F}_{2}$ our new equidistant pumping stations were located along a $500 \mathrm{~km}$ long existing pipeline, with the objective of increasing its transport capacity [1]. In this work, the stations are called A, B, C and D. A simplified scheme presents this situation in Figure 1.

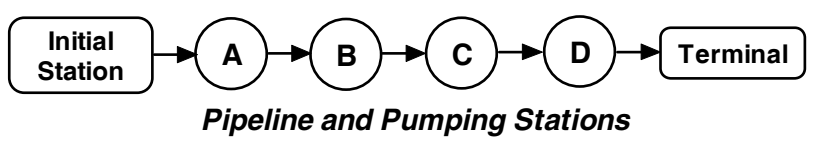

Fig. 1: Transport system including the four pumping stations.

These four identical pumping stations are fed from the 132 $\mathrm{kV}$ transmission system. Each of them has two pumps with their respective motors. Both motors have a rated power of $3500 \mathrm{HP}$ and a base speed of $1492 \mathrm{rpm}$. There is a unique drive in each plant, which is a Pulse Width Modulation (PWM) - Current Source Inverter (CSI)-Fed type. Fed at 6.6 $\mathrm{kV}$, the drive converts the $\mathrm{AC}$ voltage into $\mathrm{DC}$ and then again

(*)P. E. Issouribehere, G. A. Barbera, F. Issouribehere, and H. G. Mayer are with IITREE-LAT. Facultad de Ingeniería Universidad Nacional de La Plata (UNLP). 48 y 116. La Plata. Argentina (e-mail: iitree@iitree-unlp.org.ar). into $\mathrm{AC}$, but this new $\mathrm{AC}$ voltage has a variable frequency.

The drives of the four plants control the pumps for keeping a constant level of pressure and transported volume. During the normal process in each plant, at least one of the two pumps, commanded by the drive, works. The other pump can work too, but always with a direct connection to the $6.6 \mathrm{kV}$ busbar. In the case of both pumps running, it is the drive that first commands one of them up to the nominal conditions, and then connects it directly to the supply line. In a second step, the drive turns to command the other pump with a full control.

\section{Anomalies detected in the Plant}

When the plants began operating, some technical problems arose, and they were mainly caused by the operation of the drive. This non-linear device represents the plant main load, since the rest corresponds, basically, to auxiliary services. Essentially, two different issues were detected and, in both cases, their origin was related to the VFD operation.

On the one hand, there is a high frequency pulsing signal produced during the process of converting $\mathrm{DC}$ into $\mathrm{AC}$ at medium voltage (MV). This occurs during the generation of the variable frequency sine wave. This high frequency signal produces a spurious current which flows through the stray capacitance of the cables and generates common-mode disturbances in voltage waveform (at MV). Due to the fact that such disturbances are common-mode type, they are not present in line-to-line voltages. In addition, as the secondary of the HV/MV transformer is a delta-connection, there is no propagation of this disturbance upstream. Consequently, these disturbances are not "seen" by the Utility. Thus, it does not cause a Customer-Utility controversy. However, these common-mode disturbances caused problems in the internal installation of the plant. There were electromagnetic compatibility (EMC) problems which led to malfunction of digital protections and interference in data networks.

On the other hand, during the process of AC-DC conversion, the supply voltage is rectified at $6.6 \mathrm{kV}$ by using power semiconductor devices. This conversion process generates harmonics in the line current waveform. Depending on the distribution short circuit power, these current harmonics may or not affect the Utility voltage.

According to the current regulation in Argentina, Big Customers are required to evaluate the impact of their plants on the power system. For this reason, it is necessary to measure harmonics at the Point of Common Coupling (PCC).

What follows is a short introduction to the drives employed in each plant before a further analysis of the measurements and the obtained results. 